\title{
Design Initiative Implementation Framework: A Model Integrating Kolmogorov-Smirnov in Sustainable Practices for Triple-Bottom-Line Principles in Construction Industry
}

\author{
Dante Silva", Bernard Villaverde, Kevin Lawrence De Jesus, Lamberto Marcial Jr., \\ Raphaela Lois Ejera, Clara Vina Villa-Real, Jan Marvin Zarraga
}

School of Civil, Environmental and Geological Engineering, Mapua University, Philippines

Received May 31, 2020 ; Revised July 6, 2020; Accepted July 29, 2020

Copyright $\odot 2020$ by authors, all rights reserved. Authors agree that this article remains permanently open access under the terms of the Creative Commons Attribution License 4.0 International License

\begin{abstract}
TAGLINE: Eliminate Waste, Build Quality, Empower Team. Every construction project is characterized by being complex. Over the years, the efficiency and performance of the construction industry in the Philippines have been declining. Plus, the reality is that construction has been one of the largest polluters ever-since it started. This study proposes a plan of action that addresses these situations by introducing the concept of lean construction principles and value management. The purpose of this study is to integrate the sustainability of the construction industry in the Philippines. Sustainability was measured through triple-bottom-line. The paper explores the idea by reviewing different literatures to support theories and statements. It expands to measure the performances of the construction related to firms/companies in the Philippines, through four major categories, namely philosophy, process, people/partner and plant. The results were collected, analyzed and validated through different statistical treatments. For the last part, the researchers came up with a program that consisted of 20-suggested strategies which would help on eliminating waste, building quality and empowering team.
\end{abstract}

Keywords Sustainable Practices, Value Management, Lean Construction Principles

\section{Introduction}

A good project depends on how it is handled by professionals such as project managers, contractors, engineers, architects and such. In this research, the group defined the key roles of project managers into three categories, in particular, project and resource strategic plan, project team organization and motivation as well as making sure that customer is satisfied. Leadership skills are some of the essential techniques an engineer or contractor must have in the construction project to achieve optimum performance. This research does not concentrate on the environment itself. Sustainable objectives can be fulfilled when the correct strategies are implemented [1]. Triple Bottom Line (TBL) proposes that instead of focusing on the traditional one-bottom- line there should be three, specifically economic, social and environmental. It co-relates the economic, social and environmental to form the sustainability of a company. On account of the increased activity in construction, the need for building materials is growing that can generate adverse environmental effects. Sustainable construction is among the primary concerns which the construction industry needs to tackle/address [2].

A lean construction principle was derived from the Toyota way principles that have evolved and were successfully implemented in manufacturing [6]. Meanwhile, the sole purpose of Value Management is to enhance organizational process of carrying out tasks while increasing effectiveness and efficiency while improving the decision-making of the team [7]. The issues of sustainability should also incorporate value management, since they would affect or bring impact to the consistency of the final outcome [8]. Lean Construction Principles and Value Management are known to be interchangeable due to their similarities in having the same vision and goal to provide value to clients and building users [9]. As shown in figure 1 , the researchers formed the idea of measuring the 
key roles of project managers and the sustainability of a firm by using the 4 major categories (4Ps) of lean construction and value management principles which are philosophy, people and partner, process and plant.

The whole research revolved around the 4-P model of lean construction and value management. One of the literatures' objectives is to show ways wherein people involved in the construction industry can make changes in delivering sustainable projects and achieving sustainable goals [10]. In other words, the significance of the project is improved by focusing on its growth and progress from the definition to the process of completion of the project [11]. This fishbone analysis in figure 2 shows the most common theories/problems why the construction industry is struggling in terms of sustainability application. The research utilizes different statistical analyses such as Kolmogorov-Smirnov test, Mann-Whitney-U test, Pearson's Correlation and Analysis of Variance and such to come up with a designed program implementation framework in order to deliver sustainable practices in the construction industry.

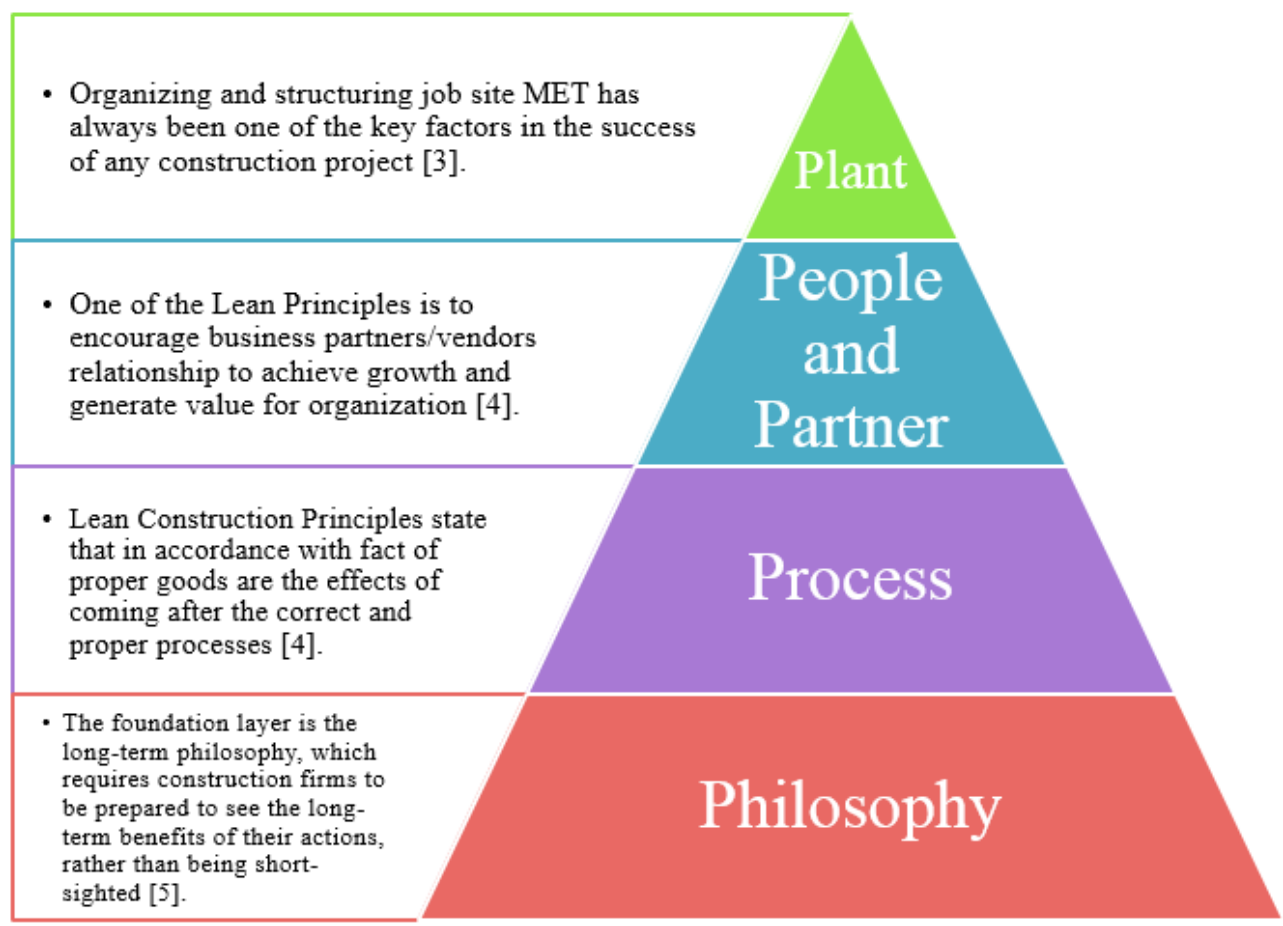

Figure 1. 4-P Model

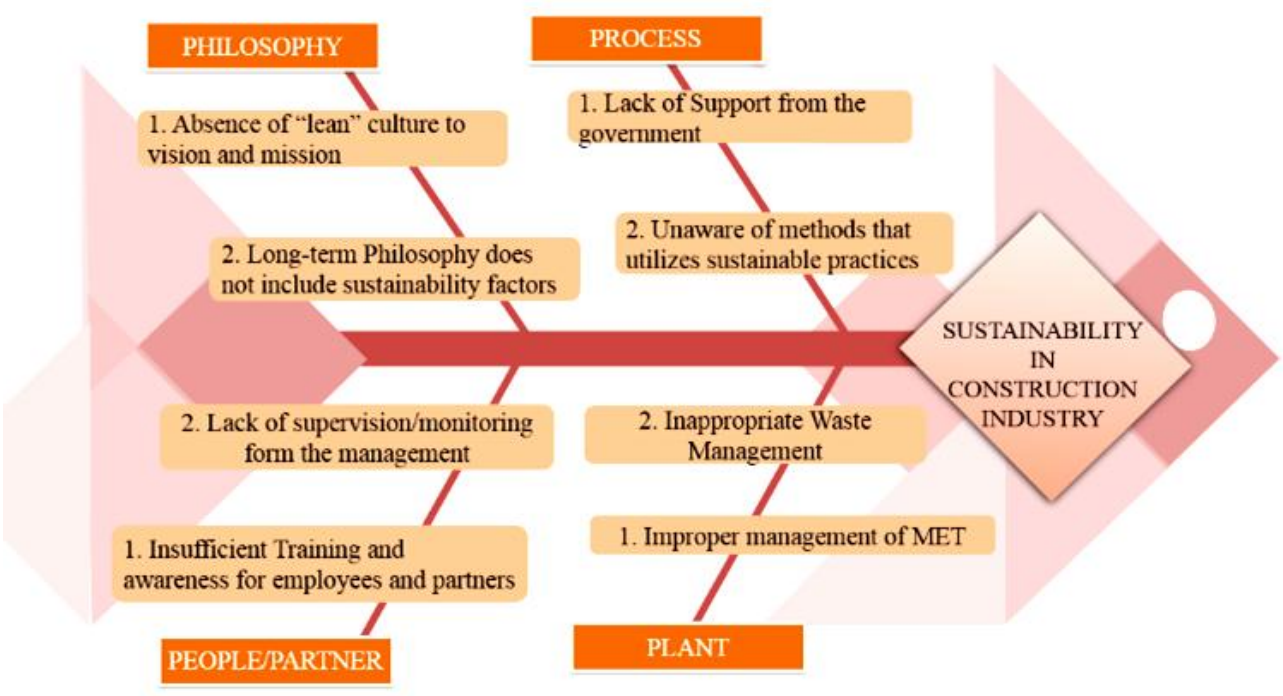

Figure 2. Fishbone Analysis 


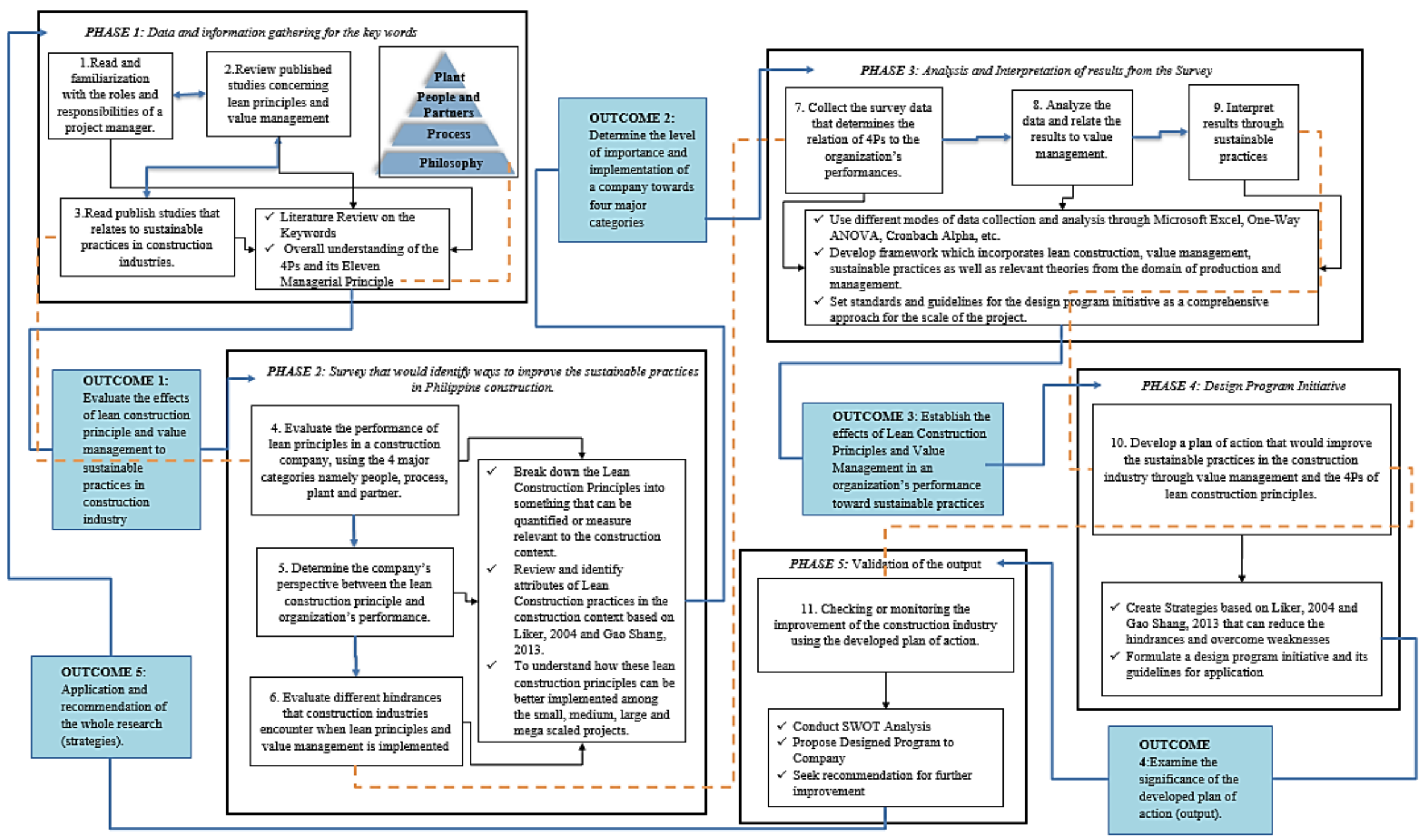

Figure 3. Conceptual Framework 


\section{Methodology and Conceptual Framework}

The research undergone through five phases in conjunction with eleven stages as illustrated in figure 3 . In this way, the researchers utilized this as a tool to achieve the main objective of the study. The phases are arranged in an order wherein the data and results would not be compromised. The whole methodology part of the research follows this order:

Phase 1: Data and information gathering of the keywords

Throughout phase 1, valuable knowledge and theories were obtained. The researchers were able to correlate the key words to the roles of project managers. Most importantly, this phase served as a good foundation for producing a survey questionnaire that enabled the researchers to evaluate the performance of lean construction principles and value management in a sustainable construction project.

Phase 2: Survey that identified ways to improve the sustainable practices in Philippine construction

The objective of this phase is to identify the application level of lean construction principle in the construction industry. Utilizing the 4 major areas of lean construction principle, namely philosophy, people/partner, process and plant as a measurement for an organization's performance is the whole point of this phase. Some hindrances and interferences that the companies meet when it comes to lean principles were proposed and evaluated. The respondents who worked on a project that ranged from small-scaled projects to mega projects came from construction companies.

Phase 3: Analysis and Interpretation of results from the Survey

The goal of this phase is to show the relationship between lean construction principles to the performance of an organization. This phase used different statistical treatments such as Pearson's Correlation Coefficient, Kolmogorov-Smirnov Test, Mann-Whitney U-Test and One Way: ANOVA to properly calculate the results and to clearly comprehend the variables of the study.

\section{Phase 4: Design Program Initiative}

This phase aims to develop a design program initiative that would improve the sustainable practices as well as alleviate the responsibilities and roles of the project managers in the Philippine construction industry. This concludes the project by answering the objectives that were set by the researchers.

Phase 5: Validation of the output

To validate the study, the authors implemented two methods to do it. The first phase was to conduct another constructive survey that proves the effectiveness of the applied developed strategies in construction firms. The second phase includes the group which would submit a presentation-copy of the research to a selected firm. This step aims to validate the designed program/strategies and collect some possible recommendations for the betterment of the research.

\subsection{Statement of the Problem}

The primary purpose of this research is to develop a design program initiative that would integrate the sustainable practices in the construction industry through Kolmogorov - Smirnov test of value management and the 4Ps of lean construction principles.

Specifically, this research aims to address the following:

1. Determine the effects of lean construction principles and value management when implemented in the construction industry through related literature and analyzed results.

2. Measure the performance of lean construction principles, through the use of four major categories, namely philosophy, people and partner, process and plant by using Analysis of Variance and Kolmogorov - Smirnov test.

3. Establish the implementation Lean Construction Principles and Value Management to help improve the organization's performance through the use of Pearson's Correlation Coefficient and Mann Whitney U test.

4. Prove that with the use of value management and the 4Ps of lean construction principles, sustainable practices can be integrated into construction projects applying the relation of Analysis of Variance to related literature and studies.

5. Determine and evaluate the hindrances that may hinder the implementation of the Lean Construction Principles and Value Management when implemented in the Philippines' construction firms through the use of Kruskal-Wallis H-values.

\section{Results}

\subsection{Specific Objective 1}

The thorough reading and analyzing literatures were the methods used for this objective. Claims were tested by relating it to the results of the survey that was conducted. Lean construction principles have positive effects on companies and firms. Since lean construction aims to improve production through labor force, activities in construction are directly affected [12]. Indeed, value management has a great deal from financial benefits along 
with the help of improving the discipline of an individual or group at a particular time [13]. It can be concluded that lean construction principles and value management affect the construction industry by improving production, providing a decrease in duration, enhancing agreements and utilizing team-based methods.

According to the results of Cronbach Alpha as shown in figure 4 , the eleven parameters exceeded the recommended data which is 0.7 (Good) and the results were excellent because they are in the range of 0.9. thus, proving that the following claims are true and valid.

\subsection{Specific Objective 2}

The Lean Construction Principles contain major categories, namely: Philosophy, Process, People and Partners, and Plant.

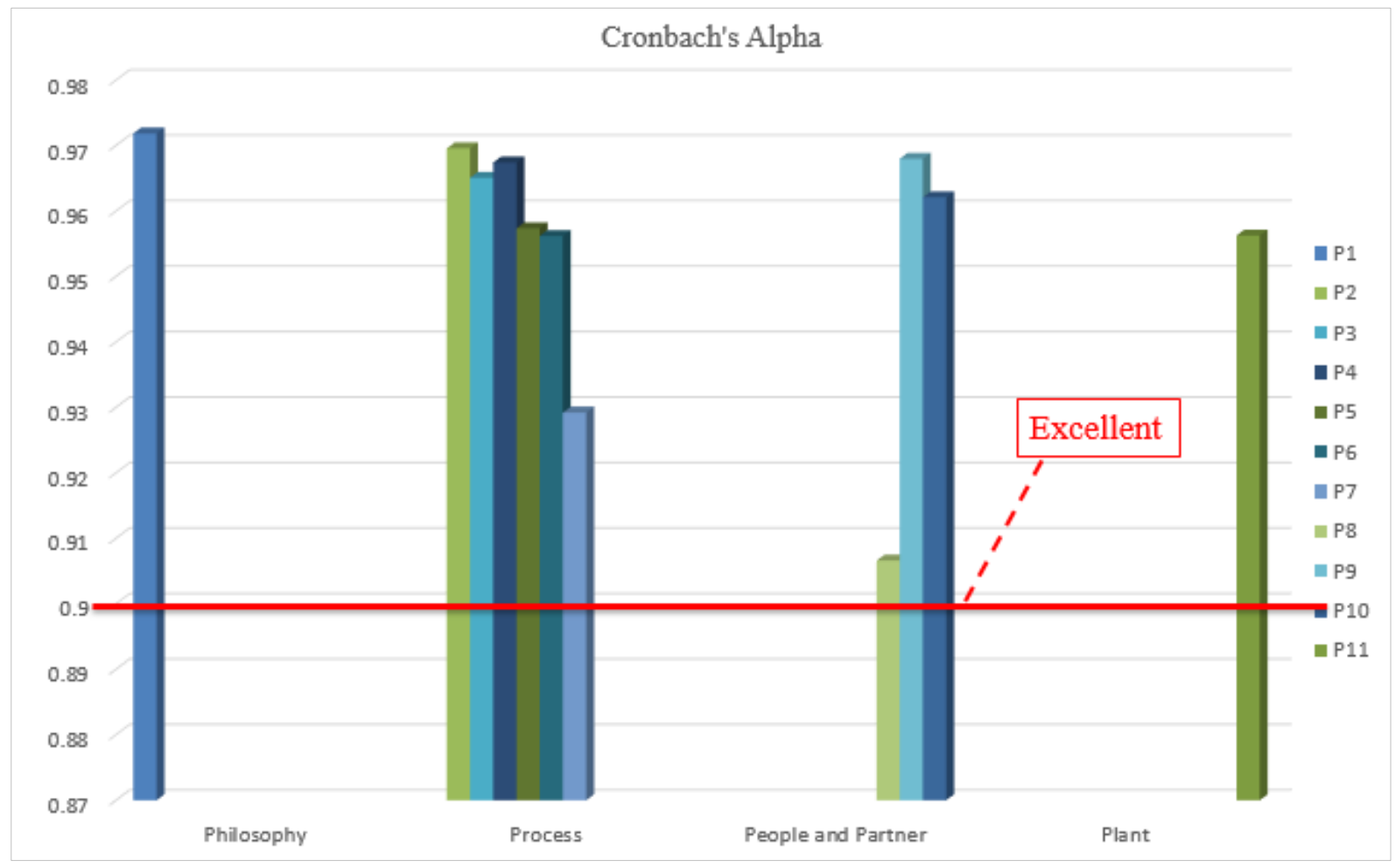

Figure 4. Results of Cronbach Alpha 


\subsubsection{One Way: Analysis of Variance}

Philosophy Model (P1). Understanding the philosophical mission defines the foundation of an organization to work and to bring the organization towards the next level. As stated, the value of "constant purpose" should be the organization's most important obligation and priority [14].

Through this treatment, the hypothesis was accepted since the P-value was less than 0.05 as seen in Table 1. This means that the relationship of respondents to applying the said philosophy/activities is acceptable and valuable. Based on the summary and average of the respondents' answers, most of them value their long-term philosophies.

Based on the model it includes one principle that incorporates seven attributes. As depicted in table 2 it is clear that the participants gave greater value to all of the attributes. Meanwhile, figure 5 shows that among these, P1.3 has the highest score received stands out $(\mathrm{m}=4.745)$. In general, the value of mean for the practices governed by Principle 1 was evaluated significantly by the responding organizations as for the extent of their perceived importance and application.

Table 1. Results of ANOVA- Philosophy

\begin{tabular}{|c|c|c|c|c|c|c|}
\hline \multicolumn{7}{|c|}{ ANOVA } \\
\hline Source of Variation & SS & df & MS & F & P-value & F crit \\
\hline Between Groups & 6449.6 & 4 & 1612.4 & 377.9063 & $3.41 \mathrm{E}-25$ & 2.689 \\
\hline Within Groups & 128 & 30 & 4.267 & & & \\
\hline Total & 6577.6 & 34 & & & & \\
\hline \multicolumn{7}{|c|}{ ACCEPT } \\
\hline
\end{tabular}

Table 2. Descriptive statistics of $\mathrm{P} 1$ practices in terms of the importance of performance

\begin{tabular}{|l|c|c|c|}
\hline \multicolumn{1}{|c|}{ Principles and Attributes of the Lean Construction Philosophy Model } & \multicolumn{3}{|c|}{ Importance } \\
\cline { 2 - 4 } & \multicolumn{1}{|c|}{ Mean } & \multicolumn{2}{|c|}{ Rank } \\
\hline \multicolumn{1}{|c|}{ Pong Term Philosophy } \\
\hline P1.1. Sustain a constant purpose (company vision, mission and values) & 4.667 & 0.476 & 4 \\
\hline P1.2. Have a high vision and goal to create value for workers, society and clients & 4.705 & 0.502 & 3 \\
\hline $\begin{array}{l}\text { P1.3. Have a good understanding of its core competences and seek to become an } \\
\text { expert in this field }\end{array}$ & 4.745 & 0.440 & 1 \\
\hline P1.4. Be responsible for products, employees and society & 4.725 & 0.532 & 2 \\
\hline P1.5. Understanding customer's requirement is priority work & 4.647 & 0.594 & 5 \\
\hline $\begin{array}{l}\text { P1.6. Be able to respond quickly to customers' changing demands and } \\
\text { requirements }\end{array}$ & 4.568 & 0.575 & 6 \\
\hline P1.7. Treat employees/suppliers as internal customers & 4.529 & 0.610 & 7 \\
\hline
\end{tabular}

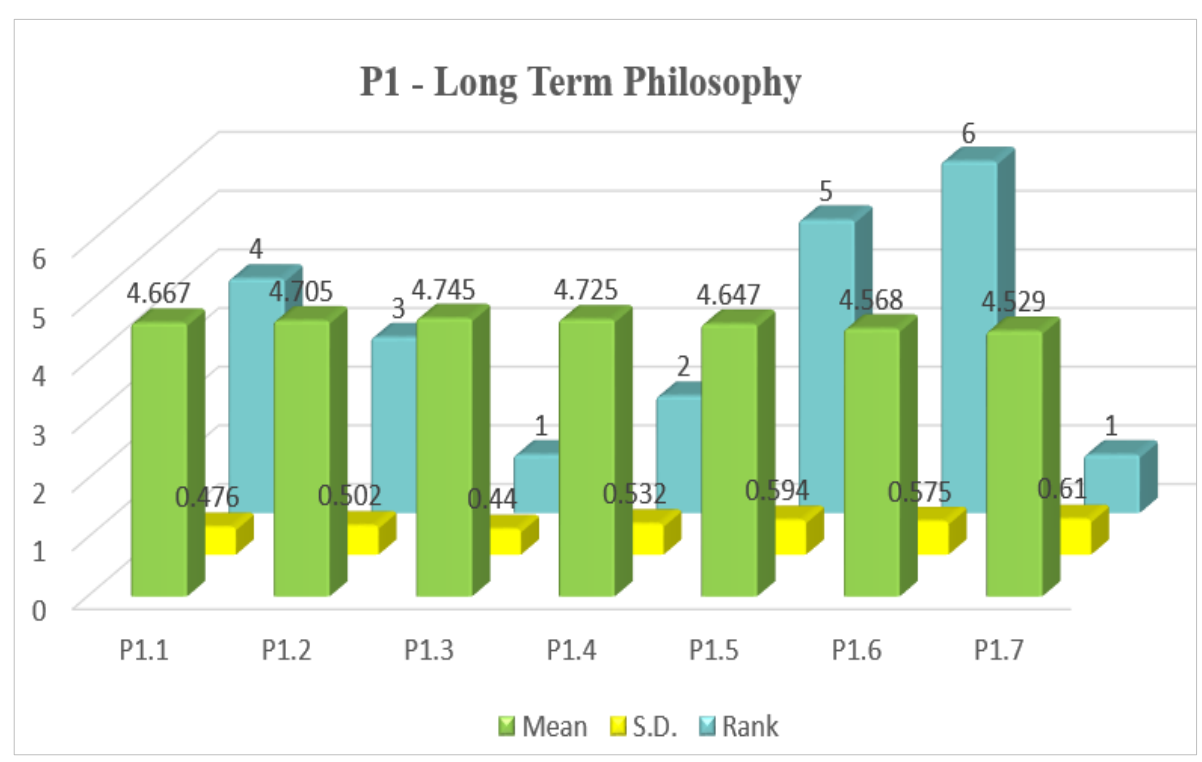

Figure 5. Average rating of respondents to the attributes in Long-term philosophy 
Process Model (P2-P7). P2 - One Piece Flow. To produce the right results, one must consider the right process as it is important to create a continuous flow that will help the firm redesign the work process. P3 - Use "pull" system. This principle promotes the system of minimizing the work process in terms of inventory. By this, it eliminates wasteful inventory. P4 - Built-in. In this principle, it promotes building a quality right the first time and stopping the problems that arise. P5 Standardized task. It is looking for the best practices by implementing procedures, then refining the standard, and turning it into a new standard that encourages innovation. P6 - Visual Control. This principle promotes a tidy and clean workplace to have a better work performance and to control the problems so there are no hidden. P7 - Use of reliable Technology. It is important to choose the best technology that fits your organization standard so that it will not interrupt the stability and reliability of the firm.
According to the results of the ANOVA: Single Factor from table 3, it seems that all the remarks from the Process model which is from P2 to P7 were all accepted and significant. This means most of them accept the idea that the Process model proposes.

Table 3. Results of ANOVA- Process

\begin{tabular}{|l|c|c|}
\hline \multicolumn{1}{|c|}{ Process Model } & P-Value & Remarks \\
\hline P2. One Piece Flow & $2.3513 \mathrm{E}-15$ & Accepted \\
\hline P3. "Pull System" & $2.4 \mathrm{E}-15$ & Accepted \\
\hline P4. Culture of Stopping & $2.25 \mathrm{E}-15$ & Accepted \\
\hline P5. Standardized Tasks & $1.72 \mathrm{E}-12$ & Accepted \\
\hline P6. Visual Control & $3.76 \mathrm{E}-11$ & Accepted \\
\hline P7. New Technology & $8.63 \mathrm{E}-12$ & Accepted \\
\hline
\end{tabular}

Table 4. Descriptive Statistics of Principle 2 practices in terms of importance

\begin{tabular}{|c|c|c|c|}
\hline \multirow{2}{*}{ Principles and Attributes of the Lean Construction Philosophy Model } & \multicolumn{3}{|c|}{ Importance } \\
\hline & Mean & S.D. & Rank \\
\hline \multicolumn{4}{|l|}{ P2- One Piece Flow } \\
\hline $\begin{array}{l}\text { P2.1. Employee is concerned with waste elimination in their daily work (Waste } \\
\text { can mean rework, poor quality, defects, waiting, etc.) }\end{array}$ & 4.431 & 0.575 & 3 \\
\hline $\begin{array}{l}\text { P2.2. In every part of the everyday job tasks material flow is applied to } \\
\text { consistently. }\end{array}$ & 4.451 & 0.673 & 2 \\
\hline $\begin{array}{l}\text { P2.3. The structure of the site is designed to maximize material flow, worker } \\
\text { movement, etc. to reduce waste due to storage, storage, transportation etc. }\end{array}$ & 4.588 & 0.606 & 1 \\
\hline $\begin{array}{l}\text { P2.4. S Aim to reduce the amount of time every task is sitting idle or waiting } \\
\text { for someone to work on it to zero. }\end{array}$ & 4.373 & 0.662 & 4 \\
\hline P2.5. Allow flow visible across the culture of organization. & 4.373 & 0.692 & 4 \\
\hline
\end{tabular}

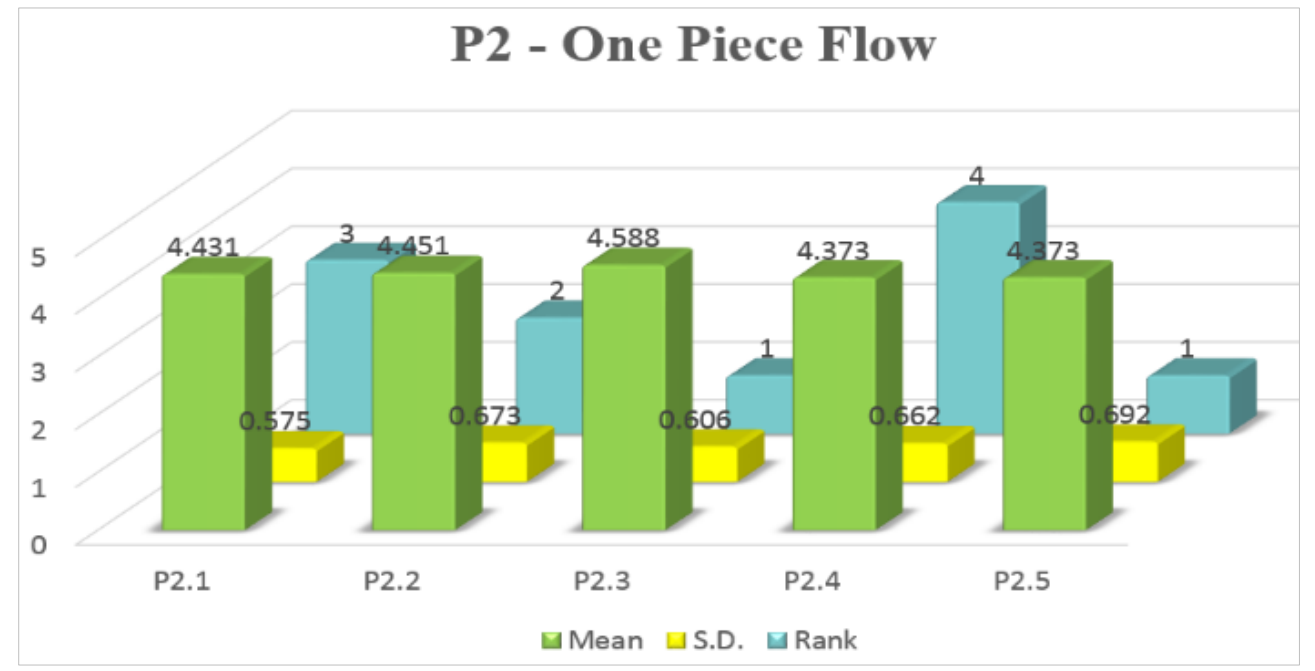

Figure 6. Average rating of respondents to the attributes in One - Piece Flow 
Based on table 4, the respondents rated the important values in a similar higher degree which reveals that all the practices are still accepted and still considered significantly by the participants. This model has 6 principles from P2 to P7 with 29 attributes. One example in the process model is the second principle under which is One - piece flow (P2). In this section, figure 6 illustrates that among the other attributes, only P2.3 $(\mathrm{m}=4.588)$ was highly classified in terms of the quality of their importance and implementation.

\subsubsection{Kolmogorov-Smirnov Test}

People/Partner Model (P8-P10). P8 - Leaders and Leadership. Leaders should be a great model that the company's employees would follow by imparting good knowledge and discipline as well as its core competencies.
P9 - Develop People and Promote Teamwork. Denoting and relating to the exceptional individuals and teams that follow the organization's philosophy represents a strong and stable culture. There comes a phase in everyone's life in which one requires belonging [15]. Employees like to know as though they're part of the organization and that their voices can indeed be considered. P10 - Respect the Extended Networks of Partners and Suppliers. To be able to show that you value your partners and suppliers it is important to assist them in achieving the targets.

Based on figure 7 , this histogram shows that the respondents of our survey strongly agree, having six questions and 5 is the highest score. Our survey comes up with a mean of 28.84 which is near to a total score of 30 .

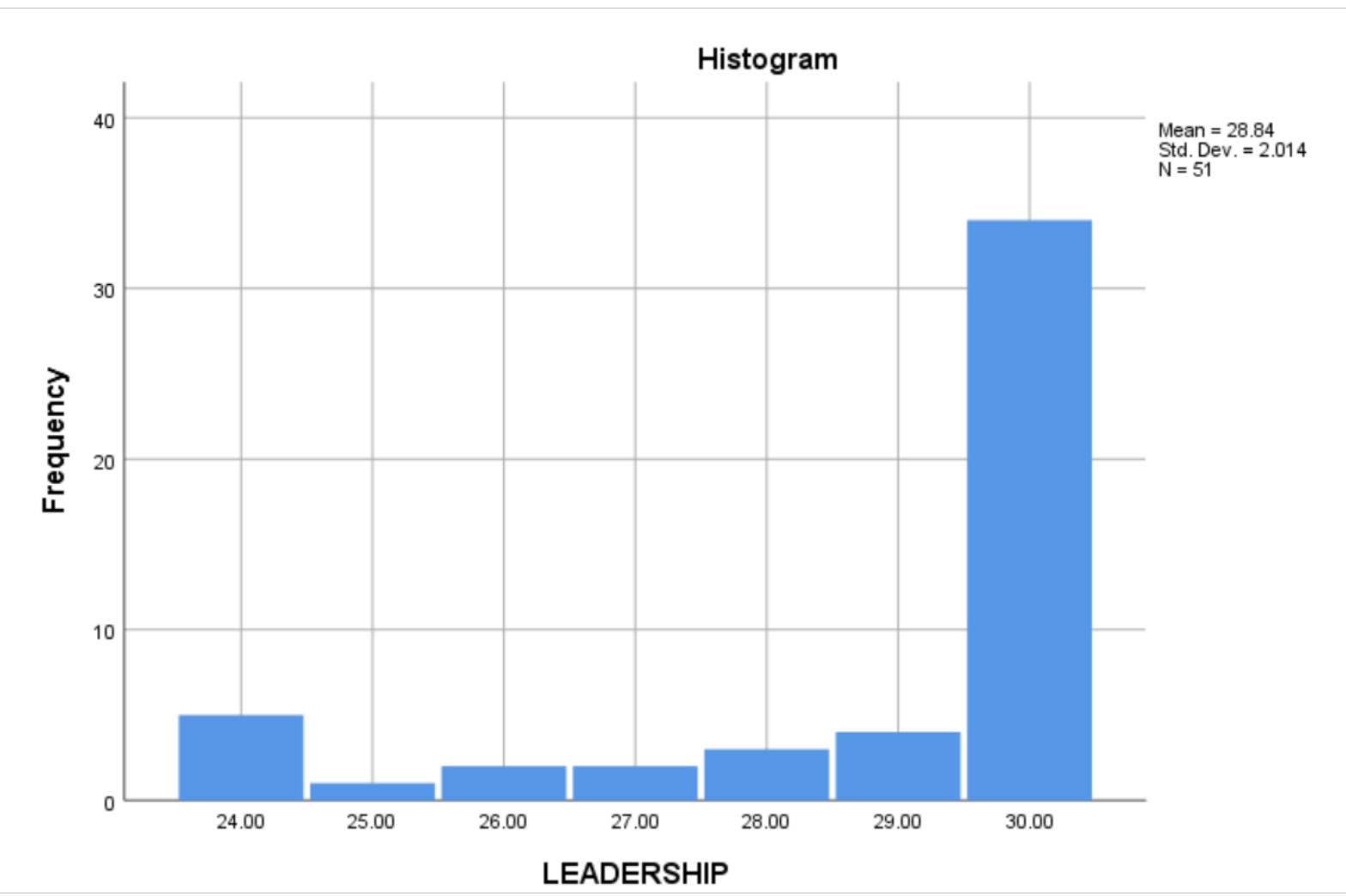

Figure 7. Histogram Results of K-S test - People/Partner 


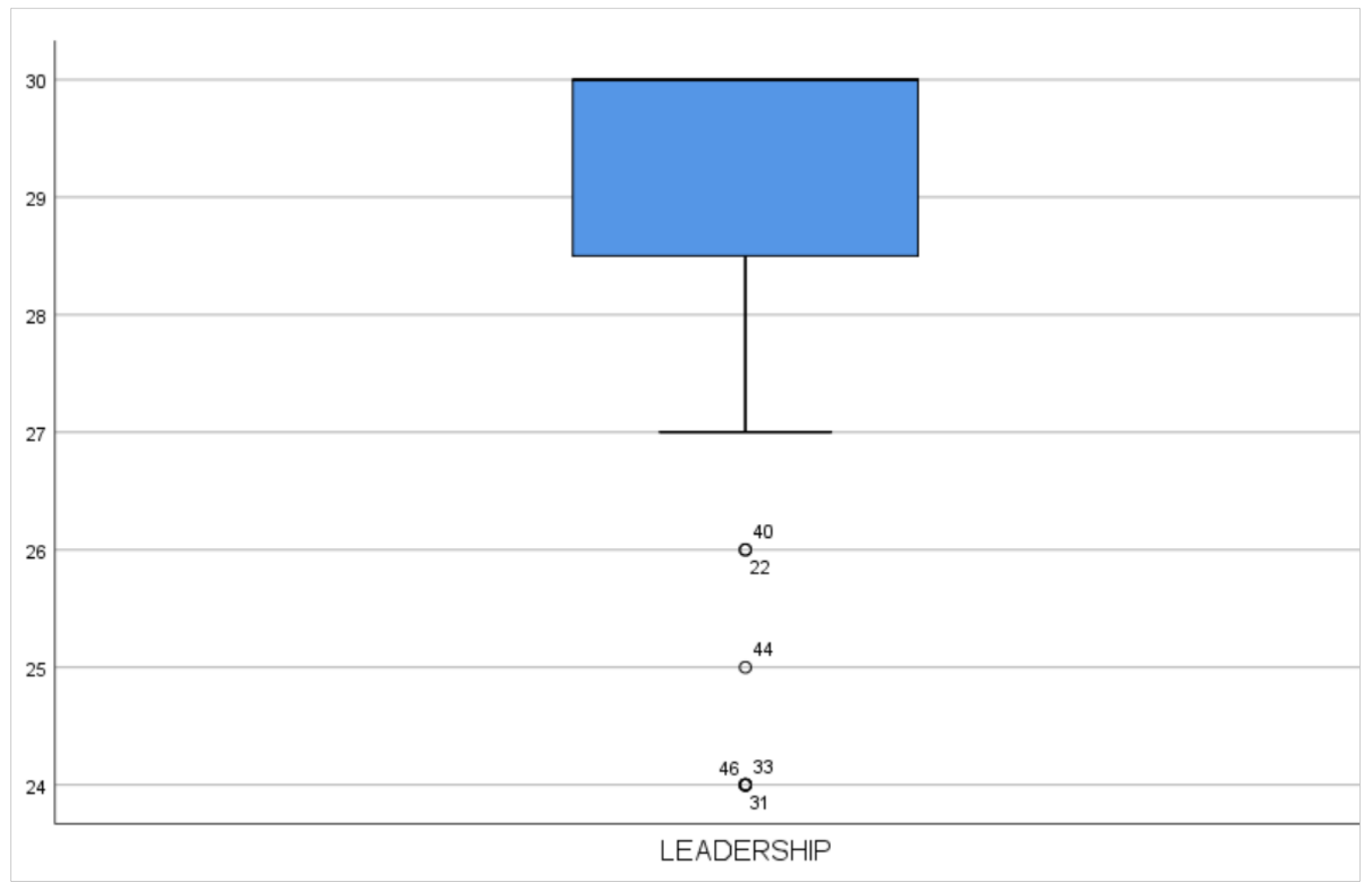

Figure 8. Box-Plot Results from K-S test- People/Partner

As shown in figure 8, this box plot illustrates that the whiskers are above 6 outliers, with the quartile 1 dividing the values from 27.5 downward and the quartile 3 dividing $25 \%$ of the data from 30.0 and above.

Plant (P11). P11 - Efficiency and Longevity of MET Selection of right Materials, Equipment and Tools, organizing and structuring jobsite, planning of daily work activities are significant in the execution phase.

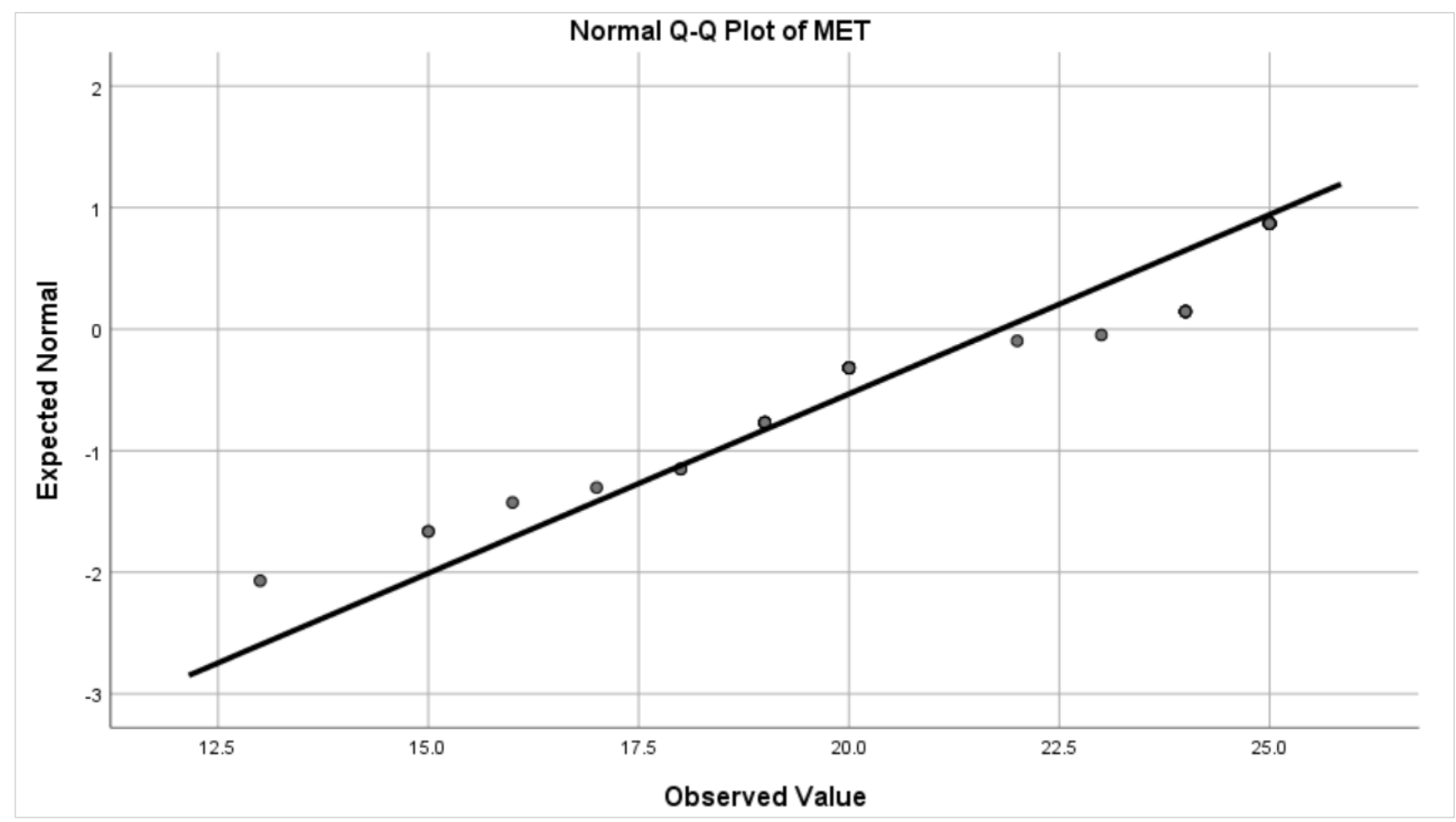

Figure 9. Q-Q Plot Results of K-S test - Plant

Figure 9 shows the Quantile-Quantile Plot wherein each principle is represented by a quantile. This Q-Q plot shows that the data from MET is normally distributed. we can see that every quantile is very close from the straight line. 


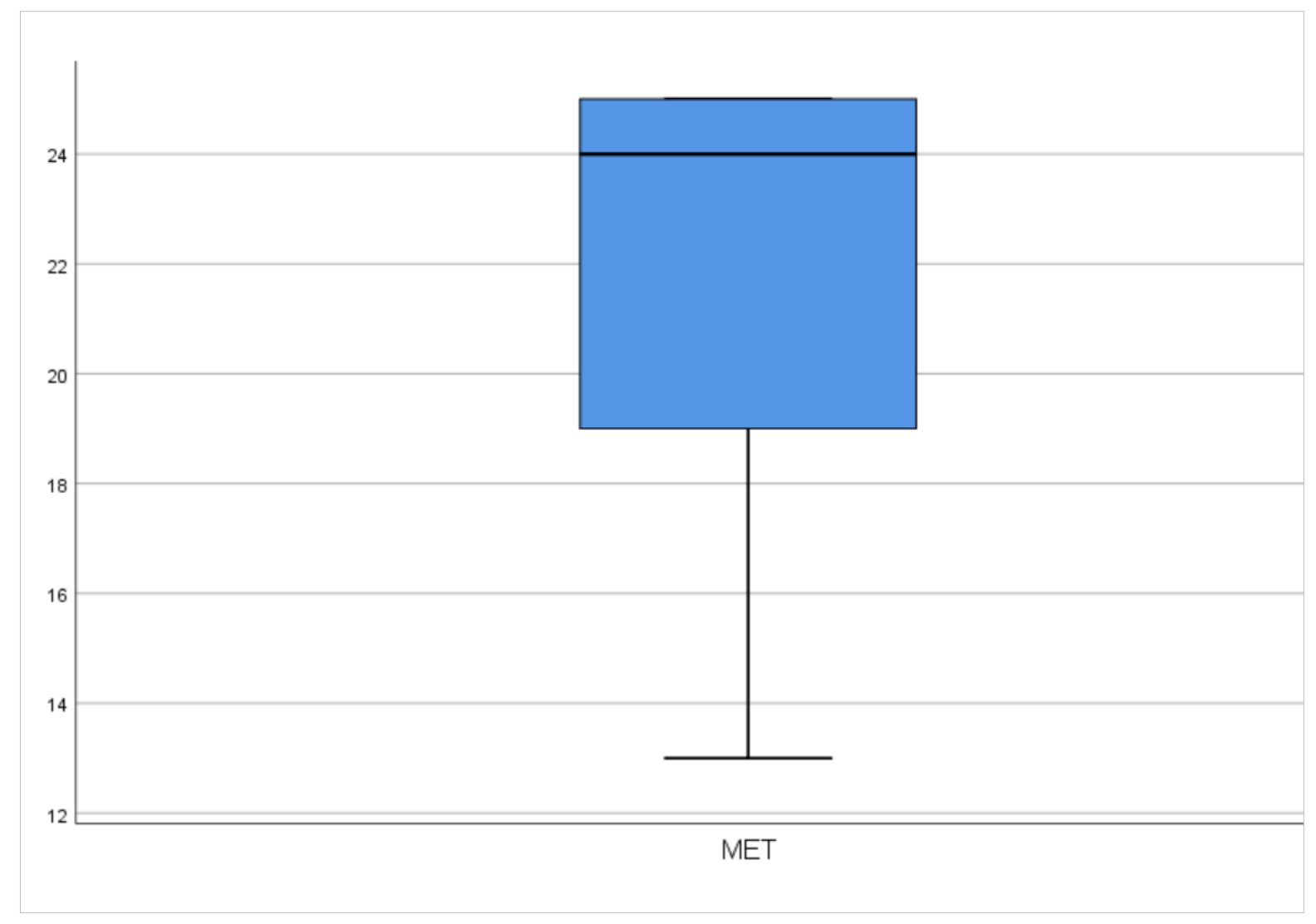

Figure 10. Box-Plot Results of K-S test - Plant

Figure 10 shows the box plot which illustrates that the whiskers are above 6 outliers. With the quartile 1 dividing the values from 19 downward to the first $25 \%$ of the data while the median is a lot closer to the quartile 3 it has a value of 24.0 and the quartile 3 dividing $25 \%$ of the data from 25.0 and above from the $75 \%$ below the quartile 3 .

Overall, the results from the Kolmogorov - Smirnov test reveal that the data was normally distributed. Based on the histogram, it shows that the data of the survey comes up with a mean value closer or near to the total score of each principle, which means that almost all of the participants agree with the said attributes. Revealing the data to be accurate because of the quantiles that lies on the straight line.

\subsection{Specific Objective 3}

The performance measurement was used to assess the correlation among eleven managerial principles and organizations' performance. These organizational performances include profitability, productivity, quality, eliminate waste on site, delivery time, and client satisfaction.

\subsubsection{Pearson's Correlation Coefficient}

As illustrated in table 5, the most significant correlation as perceived by the responding firms are eliminate waste on site which has a high correlation with use of reliable technology (P7), leaders and leadership (P8), develop people and promote teamwork (P9) and recognize the growing network of partners and suppliers (P10). Next is the delivery time which is perceived highly significant in terms of develops people and promotes teamwork (P9) and respect extended network (P10). It reveals that these principles are the best fit in improving the organization's performance in eliminating waste on site and delivery time. Figure 11 shows the average rating of respondents to the perspective on relationship among Lean Construction and Value Management on the organization's performance with the corresponding measure of mean and standard deviation with ranking. Also based on figure 11, it can be stated that the average rating of the chosen attributes for this study does not differ that much. 
Table 5. Ranks and Relation of Organizations Performance to Lean Construction and Value Management - Part 1

\begin{tabular}{|c|c|c|c|c|c|c|c|}
\hline & Prof & Prod & Qual & Elim & Del & Cli & Ave. Corr \\
\hline \multicolumn{8}{|c|}{ Lean Construction Principles Philosophy Model } \\
\hline $\begin{array}{l}\text { P1 Long Term } \\
\text { Philosophy }\end{array}$ & $0.282(\mathrm{~L})$ & $0.344(\mathrm{M})$ & $0.430(\mathrm{M})$ & $0.351(\mathrm{M})$ & $0.325(\mathrm{M})$ & $0.227(\mathrm{~L})$ & 0.327 \\
\hline P2 One Piece Flow & $0.363(\mathrm{M})$ & $0.392(\mathrm{M})$ & $0.245(\mathrm{~L})$ & $0.461(\mathrm{M})$ & $0.508(\mathrm{H})$ & $0.289(\mathrm{~L})$ & 0.367 \\
\hline P3 Use "Pull" System & $0.223(\mathrm{~L})$ & $0.205(\mathrm{~L})$ & $0.240(\mathrm{~L})$ & $0.315(\mathrm{M})$ & $0.364(\mathrm{M})$ & $0.164(\mathrm{~L})$ & 0.252 \\
\hline P4 Build in Quality & $0.325(\mathrm{M})$ & $0.126(\mathrm{~L})$ & $0.155(\mathrm{~L})$ & $0.138(\mathrm{~L})$ & $0.229(\mathrm{~L})$ & $0.273(\mathrm{~L})$ & 0.210 \\
\hline P5 Standardized Task & $0.326(\mathrm{M})$ & $0.239(\mathrm{~L})$ & $0.207(\mathrm{~L})$ & $0.388(\mathrm{M})$ & $0.383(\mathrm{M})$ & $0.324(\mathrm{M})$ & 0.311 \\
\hline P6 Visual Control & $0.483(\mathrm{M})$ & $0.383(\mathrm{M})$ & $0.356(\mathrm{M})$ & $0.563(\mathrm{H})$ & $0.557(\mathrm{H})$ & $0.409(\mathrm{M})$ & 0.459 \\
\hline $\begin{array}{l}\text { P7 Use of Reliable } \\
\text { Technology }\end{array}$ & $0.495(\mathrm{M})$ & $0.388(\mathrm{M})$ & $0.351(\mathrm{M})$ & $0.538(\mathrm{H})$ & $0.427(\mathrm{M})$ & $0.342(\mathrm{M})$ & 0.423 \\
\hline \multicolumn{8}{|c|}{ Lean Construction Principles People and Partner Model } \\
\hline $\begin{array}{l}\text { P8 Leaders and } \\
\text { Leadership }\end{array}$ & $0.299(\mathrm{~L})$ & $0.377(\mathrm{M})$ & $0.295(\mathrm{~L})$ & $0.532(\mathrm{H})$ & $0.359(\mathrm{M})$ & $0.365(\mathrm{M})$ & 0.370 \\
\hline $\begin{array}{l}\text { P9 Develop People and } \\
\text { Promote Teamwork }\end{array}$ & $0.418(\mathrm{M})$ & $0.455(\mathrm{M})$ & $0.358(\mathrm{M})$ & $0.612(\mathrm{H})$ & $0.538(\mathrm{H})$ & $0.433(\mathrm{M})$ & 0.469 \\
\hline $\begin{array}{c}\text { P10 Respect the } \\
\text { Extended Network of } \\
\text { Partners and Suppliers }\end{array}$ & $0.444(\mathrm{M})$ & $0.435(\mathrm{M})$ & $0.382(\mathrm{M})$ & $0.647(\mathrm{H})$ & $0.569(\mathrm{H})$ & $0.405(\mathrm{M})$ & 0.480 \\
\hline \multicolumn{8}{|c|}{ Lean Construction Principles Plant Model } \\
\hline $\begin{array}{l}\text { P11 Efficiency and } \\
\text { Longevity of MET }\end{array}$ & $0.367(\mathrm{M})$ & $0.379(\mathrm{M})$ & $0.272(\mathrm{~L})$ & $0.437(\mathrm{M})$ & $0.447(\mathrm{M})$ & $0.379(\mathrm{M})$ & 0.367 \\
\hline
\end{tabular}

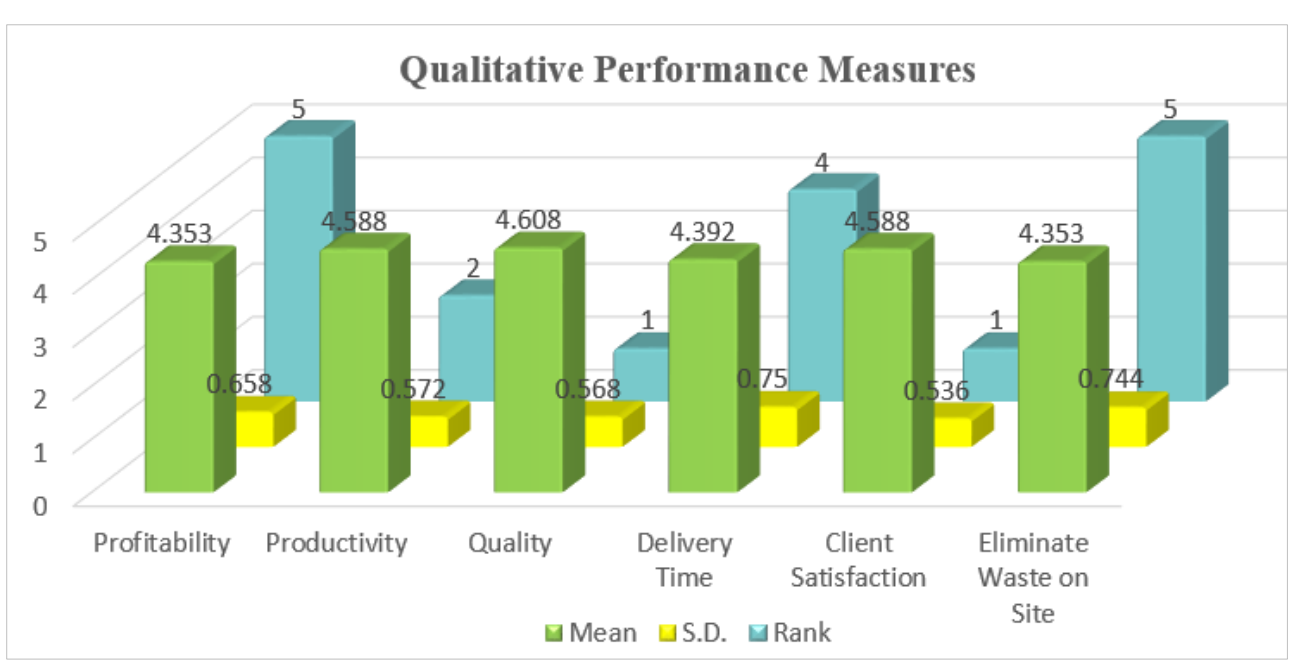

Figure 11. Relationship of Organization's Performance to Lean Construction and Value Management

\subsubsection{Mann-Whitney U Test}

Table 6. Results from Mann-Whitney U test

\begin{tabular}{|c|c|c|c|c|}
\hline & Firm & N & Mean Rank & Sum of Ranks \\
\hline Position & 1 & 28 & 29.30 & 820.50 \\
\hline & 2 & 23 & 21.98 & 505.50 \\
\hline Experience & Total & $\mathbf{5 1}$ & & 673.00 \\
\hline & 1 & 28 & 24.04 & 653.00 \\
\hline Project Type & 2 & 23 & 28.39 & 815.00 \\
\hline & Total & $\mathbf{5 1}$ & & 511.00 \\
\hline & 2 & 28 & 29.11 & \\
\hline
\end{tabular}




\section{TYPE 1-FIRM}

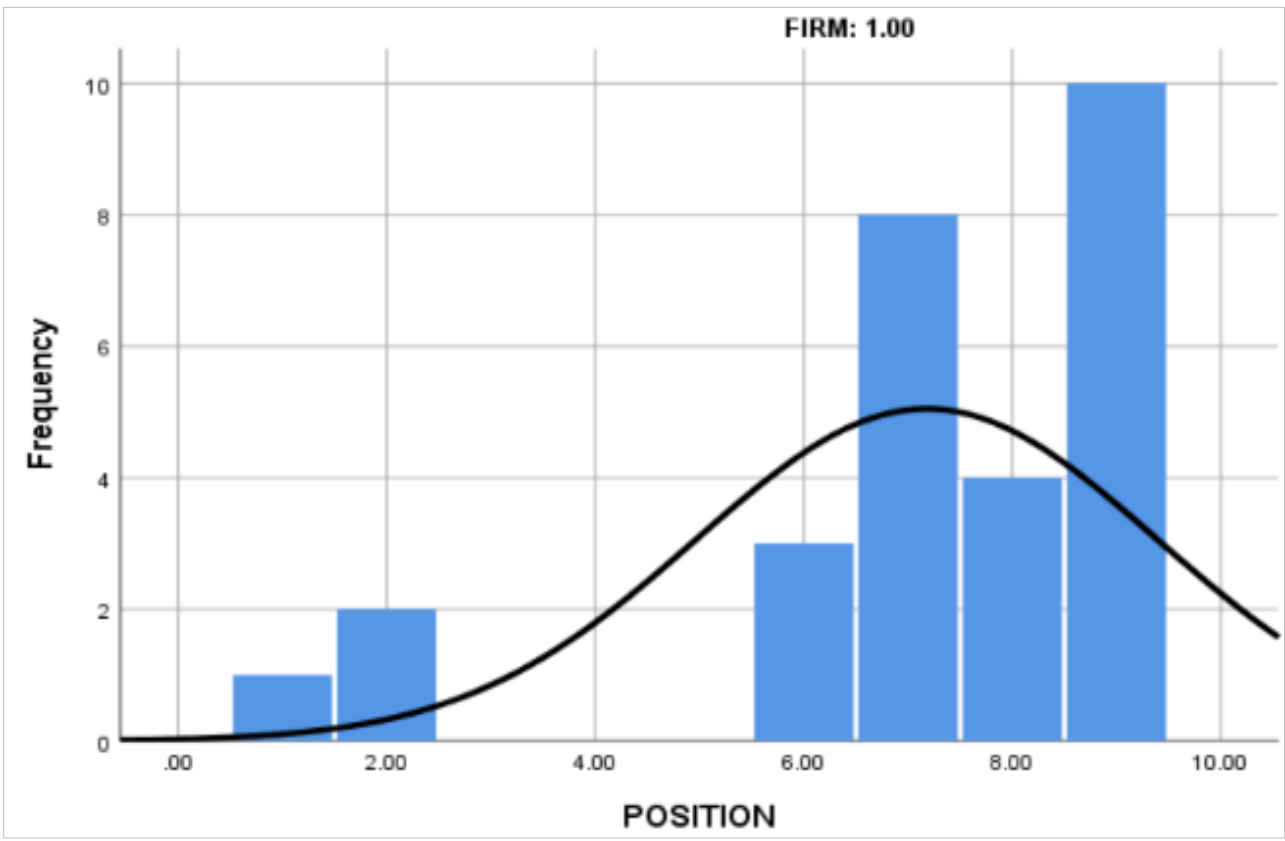

Figure 12. Relationship of Type 1 firm to Position

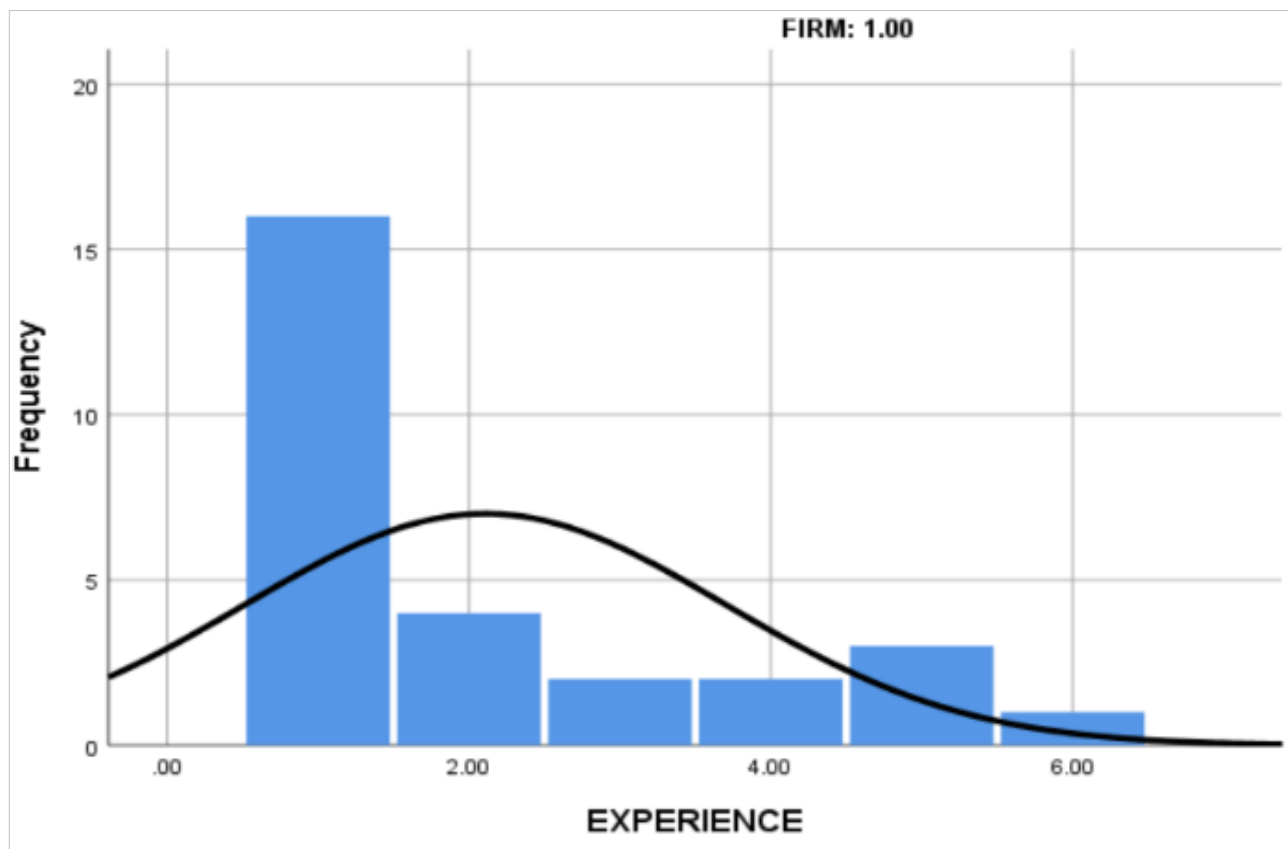

Figure 13. Relationship of Type 1 firm to Experience 


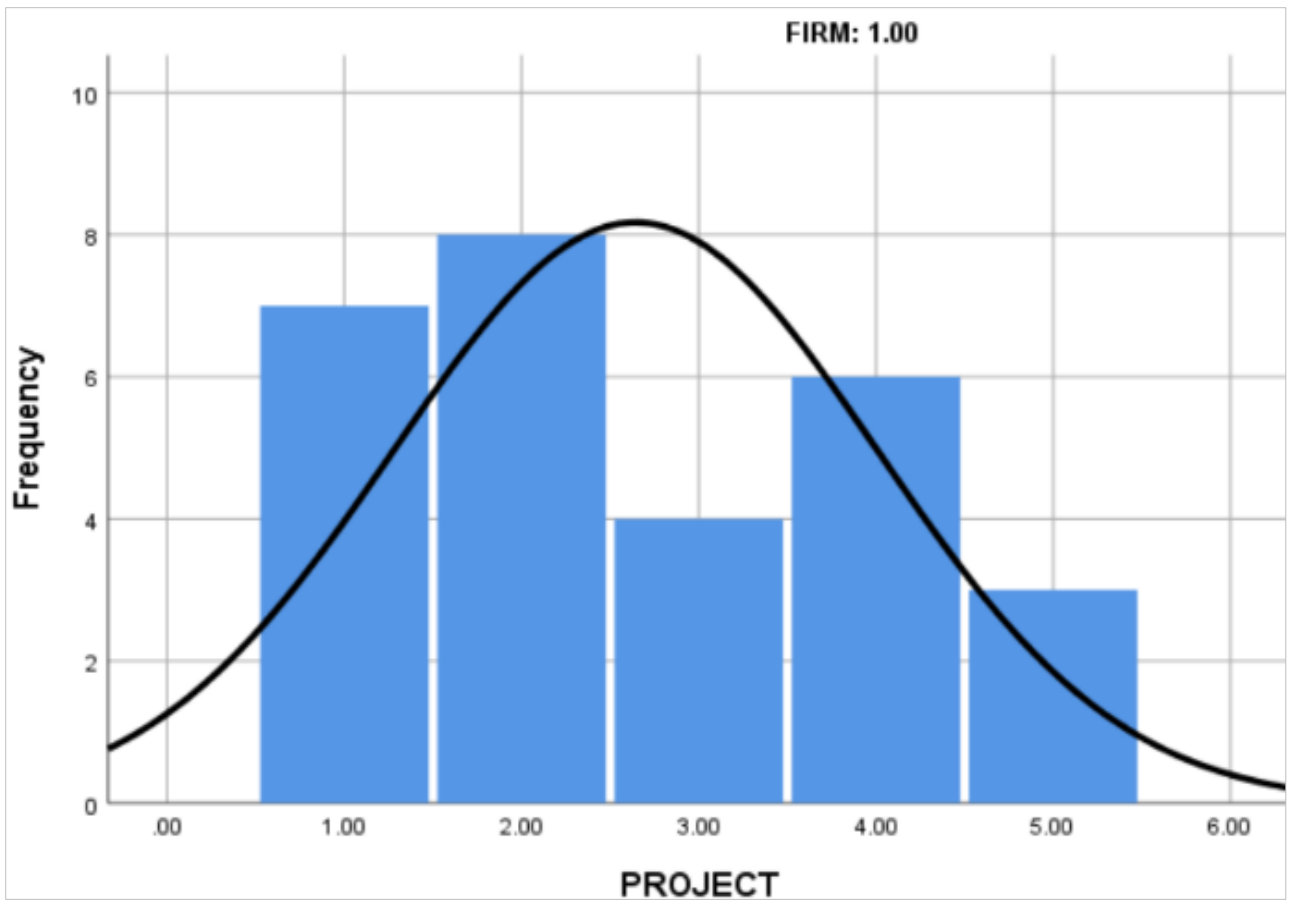

Figure 14. Relationship of Type 1 firm to Project Type

TYPE 2- FIRM

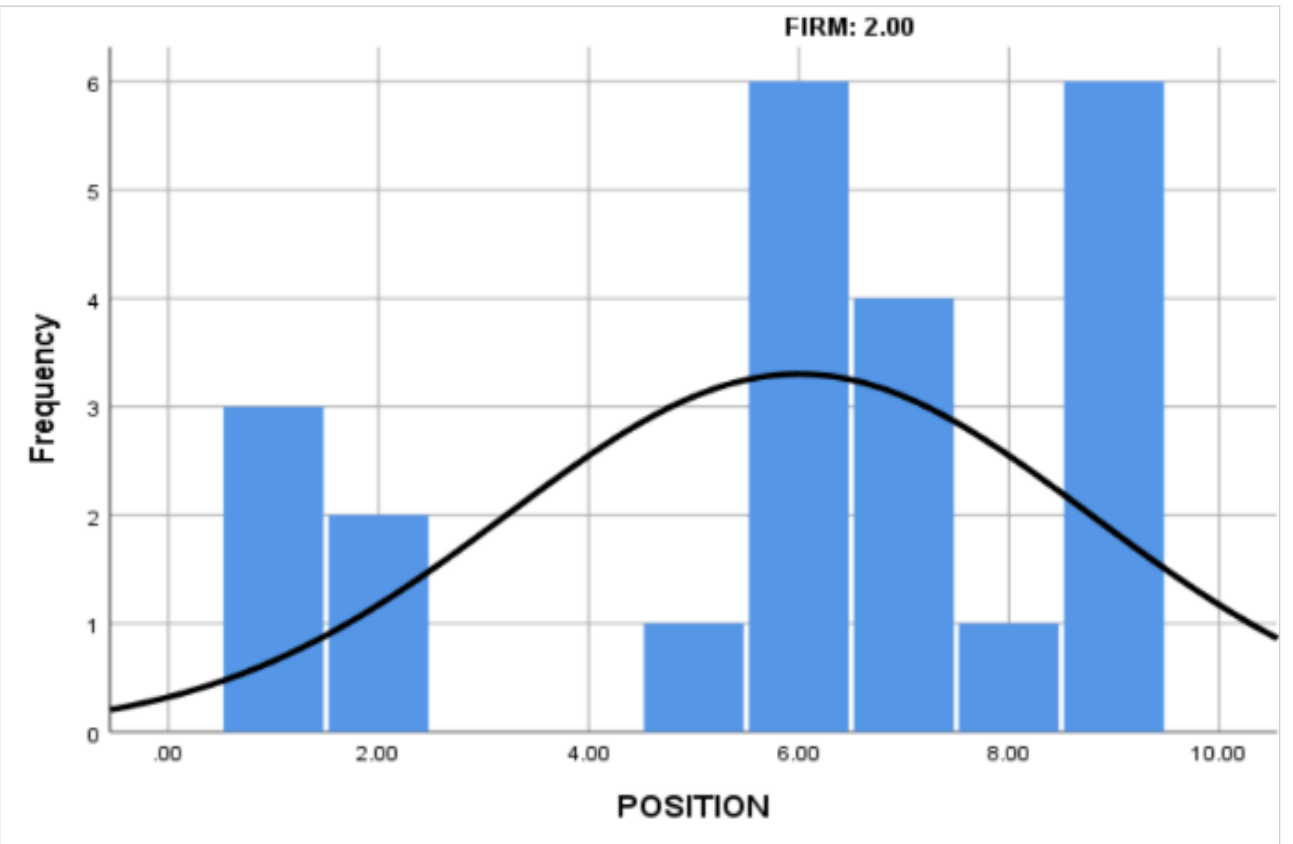

Figure 15. Relationship of Type 2 firm to Position 


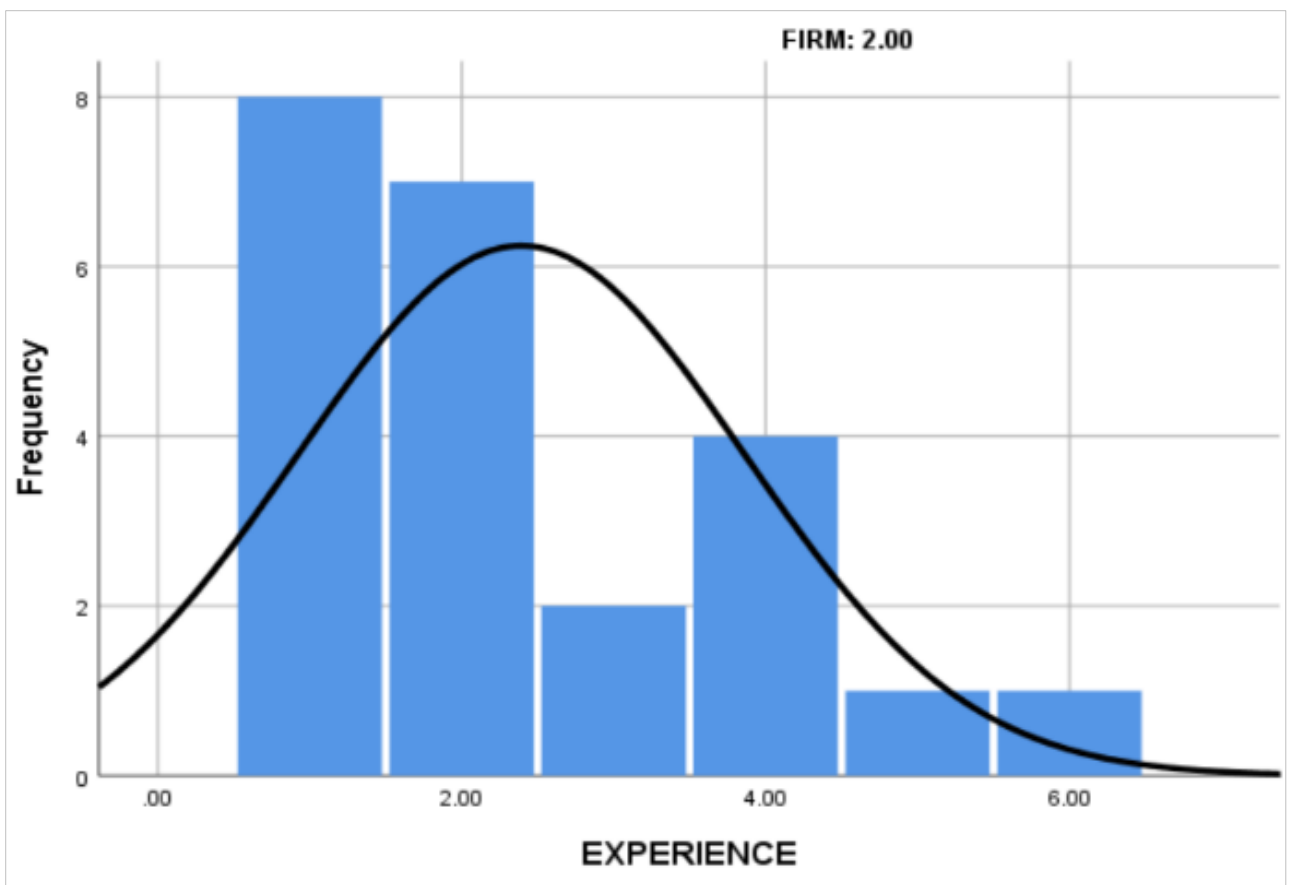

Figure 16. Relationship of Type 2 firm to Experience

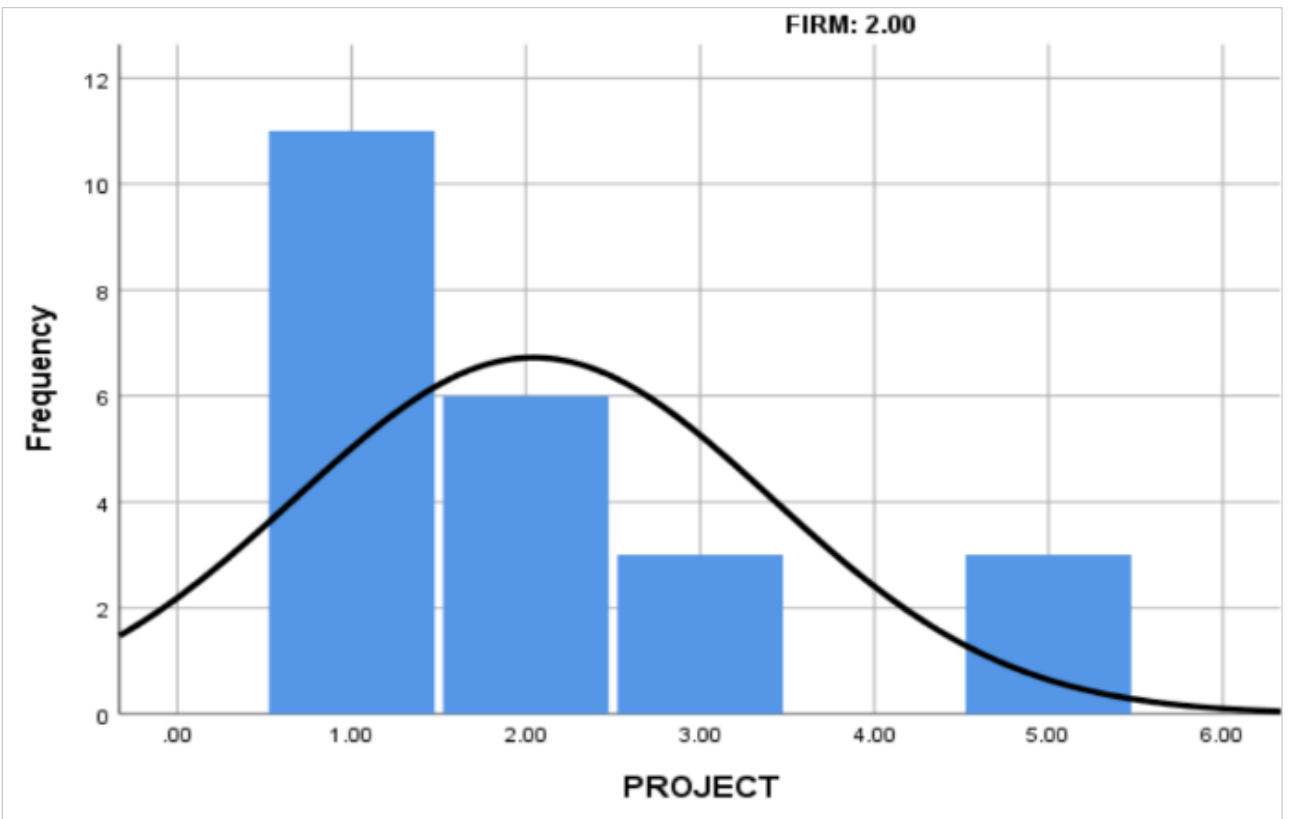

Figure 17. Relationship of Type 2 firm to Project Type

Given that, it only requires two groups which are shown from figures 12 to 17 . Firm 1 consists of 28 respondents from large to mega scaled construction projects, the relationship of these projects to position, experience and project type are reflected in figures $12,13,14$ respectively. As for firm 2 it involves 23 respondents from small to medium scaled projects, the relationships were projected from figure 15, 16 and 17. As a result from the 51 respondents, the data showed that the respondent's position, experience and project type in table 6 have nothing to do with the application of this study. This test proves that everyone that is linked to construction can use this study when it comes to their projects.

\subsection{Specific Objective 4}

Based on the results, the following can therefore be concluded. Figure 18, shows the effects of value management and 4Ps of LC principles to the triple-bottom-line of sustainability. 
In terms of LC principles, all four major categories proved that it has a drastic effect on the triple-bottom-line.

- It can be summarized that 4Ps of lean construction principles has a positive contribution to sustainable practices with regards to an environmental, economic and social factor.

On the other hand, value management can improve sustainability through specific areas such as:

- $\quad$ Environment: eco-friendly philosophy and processes that eliminate wastes

- $\quad$ Economic: methods that assess risk factors (process) and proper management of MET (plant)

- Social: multidisciplinary teamwork and forums for extended networks (people/partner)

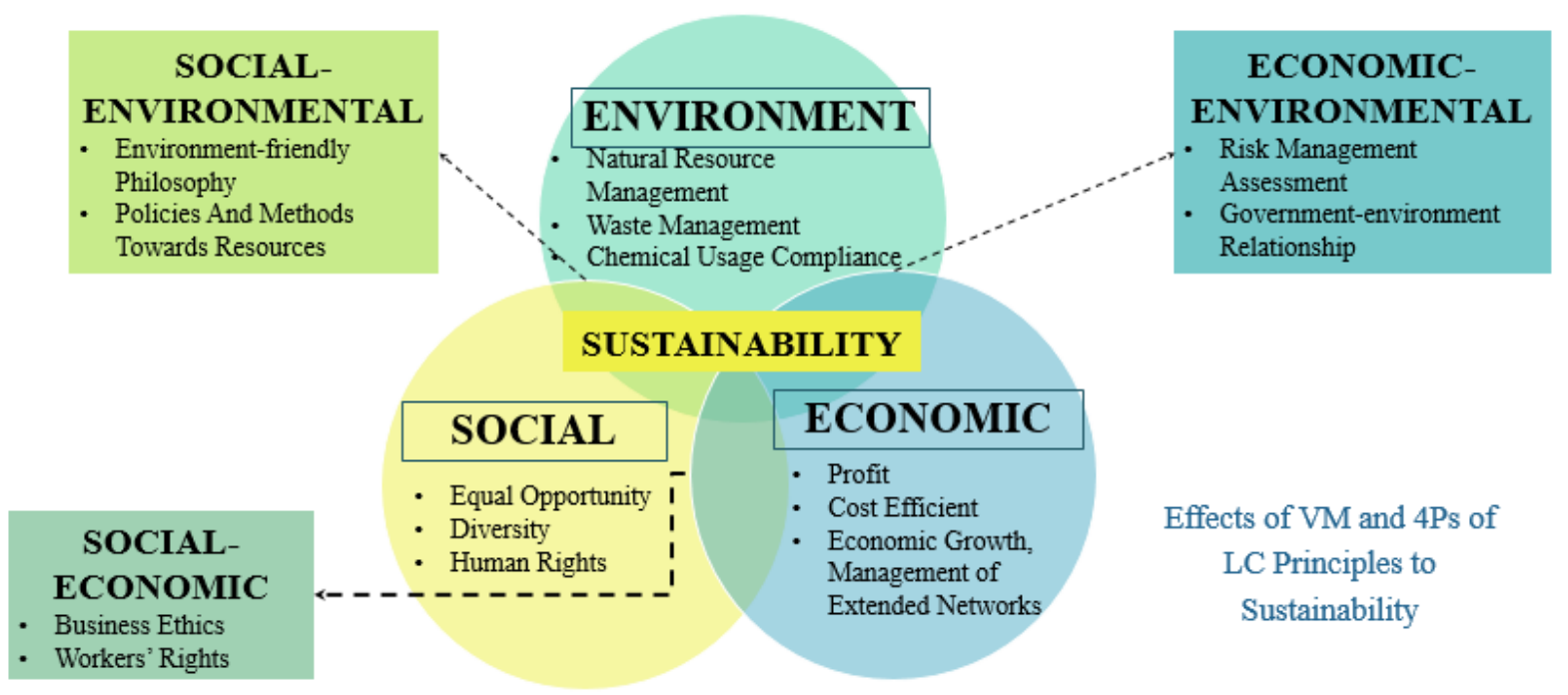

Figure 18. Effects of Lean Construction and Value Management to Triple-Bottom-Line (Sustainability)

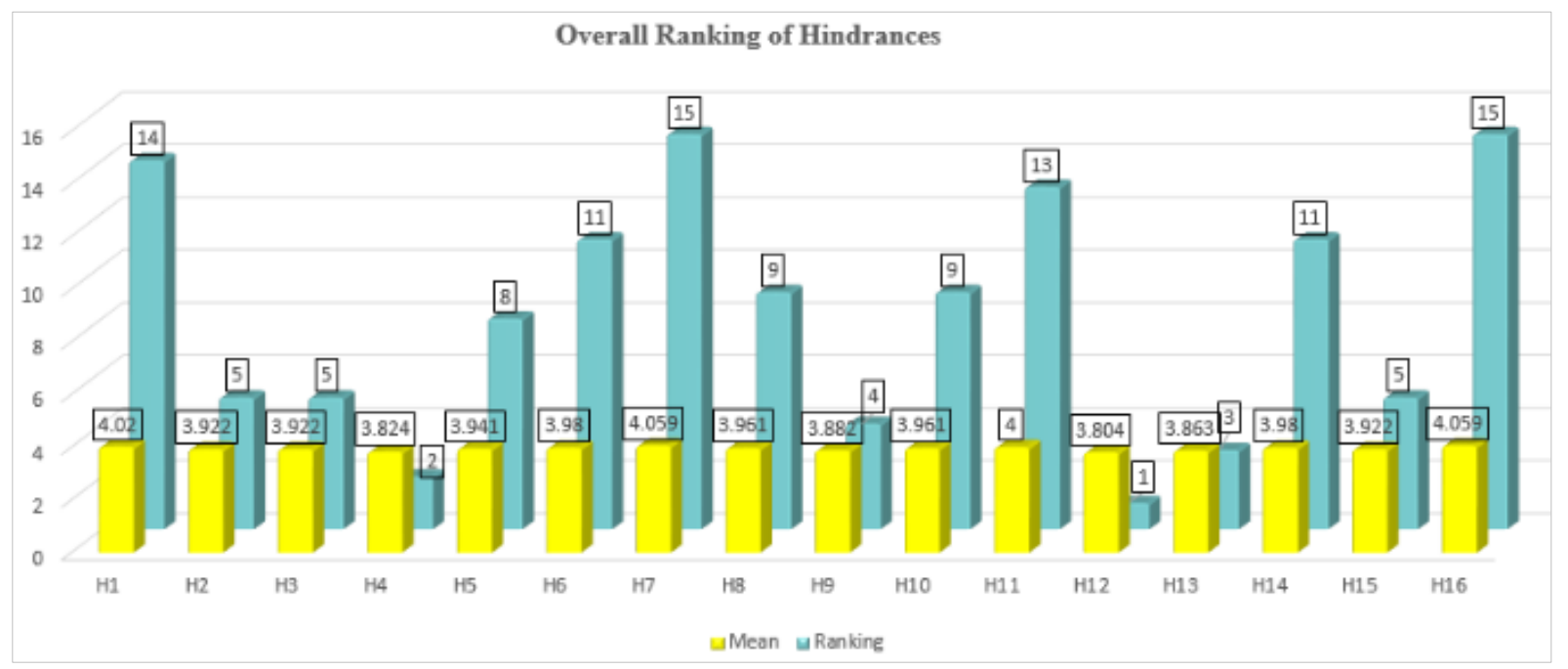

Figure 19. Overall Ranking of Hindrances to Implementing the Lean Construction and Value Management 


\subsection{Specific Objective 5}

The researchers classified 16 hindrances that may affect the construction set in the Philippines; this was established using literature and was evaluated using a survey.

Figure 19 illustrates the ranking of hindrances in implementing the eleven managerial principles. It reveals that the construction set in the small to mega scaled construction project, the most significant hindrances and challenges based from the overall ranking of the results from small to mega scaled construction projects was $\mathrm{H} 1$ : the absence of a "lean culture in the organization $(\mathrm{m}=4.02)$, H7: Insufficient training $(\mathrm{m}=4.059)$ and H16: Lack of support from the government $(\mathrm{m}=4.0)$.

\section{Conclusions}

\subsection{Sustainable Practices Strategies}

The strategies that were used and adapted by the researchers were all gathered from the resources and information learned from different literature reviews and the results of the conducted survey. The 20-strategies were the major output of the study. It is a simple plan of action that incorporates lean construction principles and value management to encourage companies to apply the sustainable practices to their company. It is also composed of strategies that enhance four major areas of a company which are philosophy, process, people/partner and plant. Here is the proposed approach based on Gao Shang [5]:

S1. Aiming to create value for consumers, workers and economy at large.

S2. Acknowledging people are the company's most significant asset; recognize and grow with them.

S3. Establishing the company's culture of prioritizing internal clients.

S4. Improving the project process by employing Value Management and Lean Construction Principles to bring and produce significant value for customers.

S5. Introducing on-site 'waste reduction' training program.

S6. Involving the stakeholders in the production process in order to maximize the quality of staff and material services.

S7. Encouraging a pull framework for items that cannot be kept on site and are prone to theft or that must meet the specifications of the customer.

S8. It is important to monitor Weekly Output Reliability; underlying causes must be uncovered, and knowledge should be gained.
S9. Aside from the complicated part of performance management tests, workers should also be motivated to provide input on quality problems, participate in performance management talks and continue providing cooperation in problem-solving, respectively.

S10. The meaning of building methods should be readily available for efficiency and often discussed with staff so that they can better appreciate the procedures.

S11. Acknowledgement for creative concepts, even for small improvements, should be promoted to strengthen the traditional approach.

S12. The use of prefabrication should be encouraged for adequate projects where standardized prefabrication components can indeed be implemented.

S13. Before executing "5S" the whole idea should be introduced to all employees through training. Note: 5S2 provides a set of practices for waste elimination, including "sort," "straighten," "shine," "standardize" and "sustain.".

S14. Efforts and attempts should be made to improve the attitude of the site environment of consumers and contractors. This will set the objective of working towards a smooth, structured, and clean place.

$\mathrm{S} 15$. Be certain that there are sufficient tools are available to incorporate a number of executive and workplace training programs on-site. This is important to recognize and develop the range, styles and a variety of trainings. Education subjects such as "identifying non-value - adding practices in the workplace," "possible change of existing job processes" etc. are worth integrating into existing training programs.

S16. Provide more opportunities for collaboration with their teams to develop future project areas and job issues. They should identify the lessons learned and share with other collaborators the best practices.

S17. Establishing learning to enhance understanding of the lean construction principles and value management for stakeholders, the ongoing communication with the contractor should be regularly reviewed and maintained to facilitate quality improvement.

S18. Establishing a "no blame and no complaints" Throughout the job. All staff will be empowered to share their views and ideas on assessments.

S19. Establishing the "continuous improvement" culture wherein, workers are encouraged to regularly take ongoing development practices.

S20. Coordinating and standardizing worksite materials, machinery, software, and services for the effective execution of projects. 


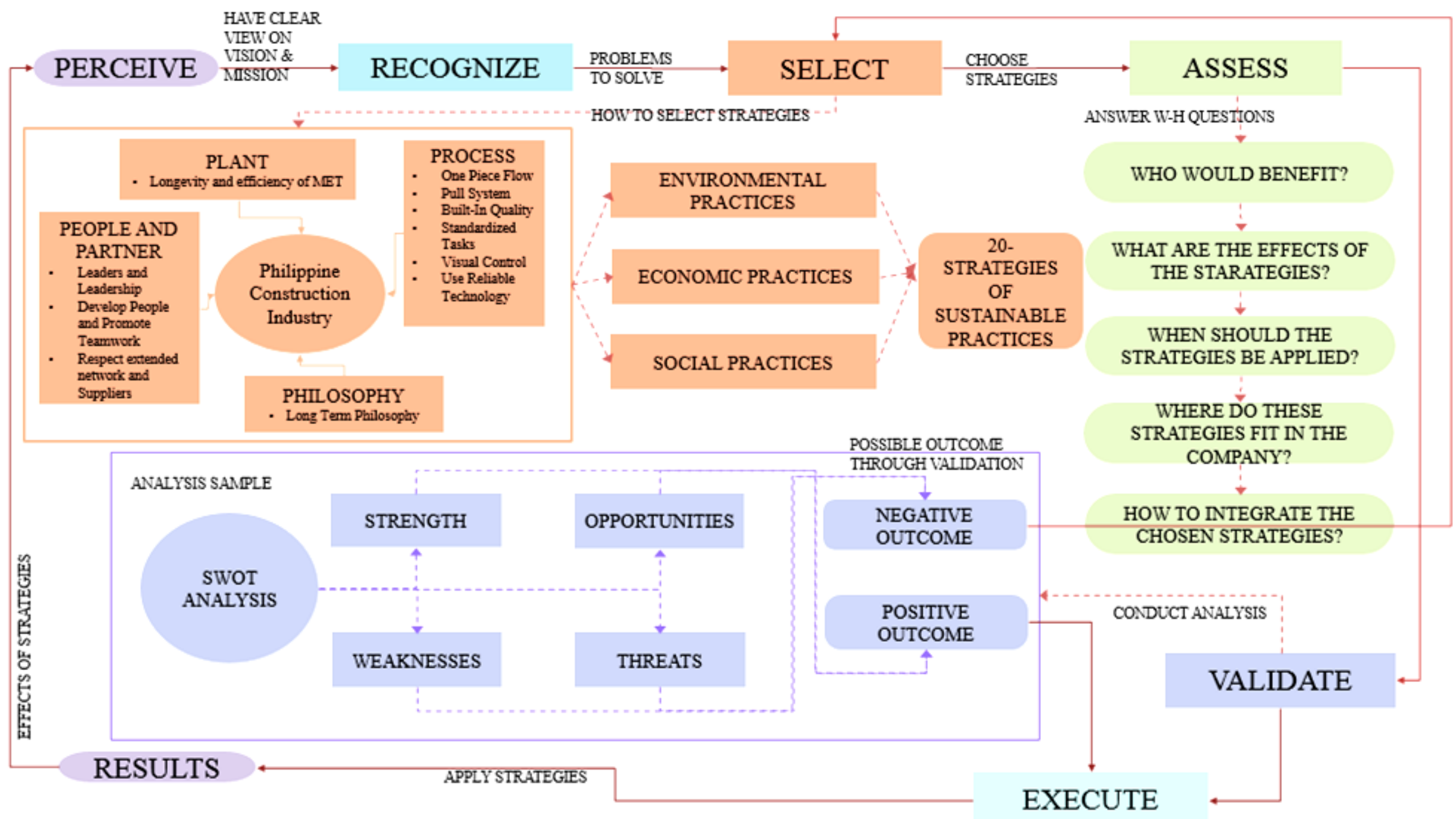

Figure 20. Design Program Implementation Model 


\subsection{Design Program Implementation Framework Guidelines}

Finally, figure 20 shows the designed program implementation framework. It presents the proposed steps towards applying the mentioned strategies in the construction projects based on the four major categories.

PERCEIVE - It is highly advisable to include lean, value, and sustainable practices to the long-term philosophy for this is the foundation of every business. Reflecting on the vision and mission would be a great start for it could be a guideline in choosing the strategies to apply.

RECOGNIZE - It is a good foundation to first recognize possible problems that would arise within the company. It is important to regularly check for areas wherein one can improve their company. Through this step, the management/managers would know where they lack and can improve.

SELECT - The company chooses the strategies to apply. They can choose one or more strategies, as long as they can accompany its applicability. This step introduces the 4Ps to the company because the strategies that were created were all aimed to improve four major areas of their company.

- As indicated in the guideline, the 20-Strategies of Sustainable Practices are composed of the four major areas and the triple-bottom-line. The most relevant and most applicable to their company's vision and mission should be the one to be selected.

ASSESS - This step evaluates the chosen strategy. This aims to answer who, what, when, where and how questions. Questions from the framework should be answered. This process enables the company to have a clear plan of action in terms of application.

VALIDATION - The company can either conduct a SWOT analysis or any type of analysis that would substantiate the assessments from step 3. Validation also gives the company a clear view of what to prioritize and value within the chosen strategy.

- As exhibited in the diagram, if the company perceived greater strengths than weaknesses and greater opportunities than threats, proceed to the last step. Otherwise, the company is encouraged to go back to SELECT

This part is the critical part for this will be the determining factor for the execution.

EXECUTION - The chosen strategy. Application of the strategy may be a challenge to the already existing company for it would be a bit different from the usual methods used. For the new or starting company, it would be a bit easier especially if their vision and mission involve sustainable practices.

RESULTS - It was observed that it would be a bit difficult to realize the changes that these strategies make in the company in the first few days or months. But it is considered that the application of these strategies is what the construction industry needs. Regardless of the effects, it is encouraged those firms to go back to step 1.

\section{Recommendations}

The following recommendations obtained from this study:

- $\quad$ The researchers suggest that to employ other methods such as observation and documentation. It is also suggested to use different statistical analysis in evaluating the gathered data.

- This program has a vast influence that can also be applied to other fields such as education, marketing, and such.

- $\quad$ The researchers recommend that stakeholders such as clients, vendors, and subcontractors be included as these groups and clusters should also recognize the 11 managerial principles. These groups can benefit from this program since they play a significant role in the implementation phase.

- It is also recommended involving the Government in the construction industry as research participants to be more committed to embracing as well as implementing the idea of lean sustainable and value management practices.

\section{Acknowledgements}

We are thankful Mapua University for the support and all the individuals essential for the completion of the study.

\section{REFERENCES}

[1] Khalfan, M. M., Bouchlaghem, D. M., Anumba, C. J., \& Carillo, P. M. (2002). A framework for managing sustainability knowledge the C-SAND approach Proc.E-Sm@Rt.Univ.of Salford, Salford U.K, 19-21.

[2] Silva, D. L., Jesus, K. L., Villaverde, B. S., \&amp; Adina, E. M. (2020). Hybrid Artificial Neural Network and Genetic Algorithm Model for Multi-Objective Strength Optimization of Concrete with Surkhi and Buntal Fiber. Proceedings of the 2020 12th International Conference on Computer and Automation Engineering. doi:10.1145/3384613.3384617

[3] Othman, A., Ghaly, M., \& Abidin, N. (2014). Lean Principles: An Innovative Approach for Achieving Sustainability in the Egyptian Construction Industry. Organization, Technology and Management in Construction An International Journal, 917-932.

[4] Ko, C.-H., Wang, W.-C., \& Kuo, J.-D. (2011). Improving Formwork Engineering Using the Toyota Way. Journal of Engineering, Project, and Production Management, 13-27. 
[5] Shang, G. (2013). The Toyota Way Model: An Implementation Framework for Large Chinese Construction Firms. B.Sc., Zhejiang Gongshang University.

[6] Aziz, R., \& Hafez, S. (2013). Applying Lean Thinking in Construction and Performance Improvement. Alexandria Engineering Journal.

[7] Kelly, J., Male, S., \& Graham, D. (2015). Value management of construction projects. Chichester, West Sussex, United Kingdom: John Wiley \& Sons.

[8] Abidin, N. Z., \& Pasquire, C. L. (2005). Delivering sustainability through value management. Engineering, Construction and Architectural Management, 12(2), 168-180. doi:10.1108/09699980510584502

[9] Musa, Muktari \& Pasquire, Christine \& Hurst, \& Alan. (2016). WHERE LEAN CONSTRUCTION AND VALUE MANAGEMENT MEET.

[10] Langston, C. A., \& Ding, G. K. (2001). Sustainable Practices in the Built Environment. New York: Routledge.

[11] Kelly, J. (2016). Value management in design and construction. Place of publication not identified: TAYLOR $\&$ FRANCIS.

[12] Erol, H. H. (2014). Identifying the Effects of Lean Construction Principles on Variability of Project Duration. Middle East.

[13] Rangelova, F. \& Traykova. (2014). Value Management in Construction Project. First Scientific- Applied Conference with International Participation "Project Management in Construction". University of Architecture, Civil Engineering, and Geodesy.

[14] Deming, W. (1986). Out of the Crisis, Cambridge, Mass: Massachusetts Institute of. Center for Advanced Engineering Study

[15] Maslow, A.H. (1954) Motivation and Personality, New York: Harper. 